\section{Commentary: Until we take it seriously, the status quo of postoperative atrial fibrillation management will prevail}

Grace Lee, BHSc, ${ }^{\mathrm{a}}$ Derrick Y. Tam, MD, PhD, ${ }^{\mathrm{b}}$ and Stephen E. Fremes, MD, MSc ${ }^{\mathrm{b}}$

New-onset postoperative atrial fibrillation (POAF) is common following cardiac surgery, developing in almost onethird of patients after coronary artery bypass grafting (CABG) and two-thirds of patients after valvular surgery. ${ }^{1}$ The long-standing characterization of atrial fibrillation (AF) as a transient and benign postoperative complication may be an underlying reason for the relatively limited progress in terms of its prophylaxis and management. ${ }^{2}$ This assumption has only recently been called into question by new studies reporting varying degrees of association between POAF and mortality, stroke, myocardial infarction, or renal failure. ${ }^{3-7}$ Accordingly, Caldonazo and colleagues ${ }^{8}$ sought to synthesize the associations between post-cardiac surgery AF and multiple adverse effects in a meta-analysis of 57 studies pooling 246,340 patients. ${ }^{8}$

Specifically, the authors performed the most recent and comprehensive meta-analysis to date, examining 9 shortand long-term postoperative outcomes. In doing so, they convincingly demonstrated that POAF is not benign by reporting its significant association with the primary outcome of perioperative mortality (odds ratio, 1.92; 95\% confidence interval, 1.58-2.33). Furthermore, they also found an increased risk of POAF with the key secondary outcomes of perioperative stroke, myocardial infarction, acute renal

From the ${ }^{\mathrm{a}}$ Temerty Faculty of Medicine and ${ }^{\mathrm{b}}$ Division of Cardiac Surgery, Department of Surgery, Schulich Heart Centre, Sunnybrook Health Sciences Centre, University of Toronto, Toronto, Ontario, Canada.

Disclosures: The authors reported no conflicts of interest.

The Journal policy requires editors and reviewers to disclose conflicts of interest and to decline handling or reviewing manuscripts for which they may have a conflict of interest. The editors and reviewers of this article have no conflicts of interest.

Received for publication April 13, 2021; revisions received April 13, 2021; accepted for publication April 15, 2021; available ahead of print April 20, 2021.

Address for reprints: Stephen E. Fremes, MD, MSc, Professor of Surgery, University of Toronto Schulich Heart Centre, Sunnybrook Health Sciences Centre, 2075 Bayview Ave, Room H4 05, Toronto, Ontario, Canada M4N 3M5 (E-mail: stephen. fremes@sunnybrook.ca).

J Thorac Cardiovasc Surg 2023;165:104-5

$0022-5223 / \$ 36.00$

Copyright (c) 2021 by The American Association for Thoracic Surgery

https://doi.org/10.1016/j.jtcvs.2021.04.034

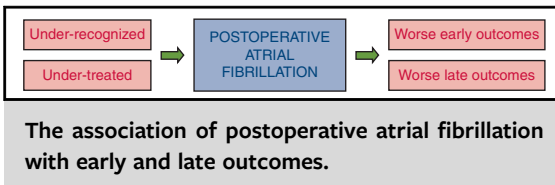

CENTRAL MESSAGE

In a comprehensive review of the

literature, postoperative atrial

fibrillation after cardiac surgery

was found to be associated with

short- and long-term harm.

failure, long-term mortality, stroke, and persistent $\mathrm{AF}$, as well as longer hospital and intensive care length of stay. These findings are well summarized and clearly presented in their Table 1. In comparison, previous meta-analyses pooled 10 to 35 studies and focused primarily on stroke and/or mortality. ${ }^{9-12}$

The authors also performed several subgroup analyses that illuminated differing effect sizes when stratified by cardiac surgery subtypes, study date, and the continuity of postoperative monitoring. Finally, their meta-regression discerned a stronger association between POAF and early mortality in participants with diabetes and previous myocardial infarction. ${ }^{8}$ The authors are to be commended on a meta-analysis that is broad in scope, methodologically robust, and well presented.

Despite the ubiquity and importance of POAF, there remains considerable uncertainty pertaining to its prevention and management. The 2014 American Heart Association (AHA)/American College of Cardiology (ACC)/Heart Rhythm Society (HRS) guidelines recommend rate control with beta-blockers (class I LOE A) as first-line therapy and amiodarone as prophylaxis (class IIa LOE A). ${ }^{13}$ However, the 2019 Focused Update of the AHA/ACC/HRS guidelines provided no specific recommendations for post-cardiac surgery patients despite several recent developments. ${ }^{14}$ Gillinov and colleagues ${ }^{15}$ addressed the rate versus rhythm control question in 2016 and found no net clinical advantage to either approach. The necessary duration of treatment or window of observation is relevant. Gillinov and colleagues ${ }^{15}$ followed patients for 60 days, whereas Caldonazo and colleagues affirmed the importance of POAF long-term. More recently, using the Society of Thoracic Surgeons Adult Cardiac Surgery Database, ${ }^{16}$ Matos and colleagues ${ }^{17}$ evaluated the postoperative administration of oral anticoagulation and amiodarone and discovered substantial variability in the application of anticoagulation, but increased 
bleeding rates and few short-term benefits associated with its use. The questions arising from this investigation are currently being addressed in a randomized study comparing anticoagulation (warfarin or direct oral anticoagulants) with antiplatelet therapy, the Anticoagulation for New-Onset Post-Operative Atrial Fibrillation After CABG (PACES) trial (NCT04045665). ${ }^{18}$ Furthermore, the emergence of wearable miniaturized monitors may better inform the true incidence of POAF postdischarge and the optimal duration of treatment in individual patients compared with surface electrocardiography or short-duration Holter monitoring. ${ }^{19}$

That being said, this review should be interpreted in light of several important limitations. Although Caldonazo and colleagues analyzed a variety of baseline variables, the inherent nature of meta-analyses pooling observational studies precludes the formation of causal inferences. Substantial heterogeneity existed across many pooled outcomes, including perioperative and long-term mortality, the sources of which were not explained. Finally, the number of hypotheses tested increases the risk of a type 1 error. $^{8}$ Nevertheless, Caldonazo and colleagues have completed an exhaustive meta-analysis of the available evidence on early and late outcomes associated with POAF. By highlighting its serious impact, this meta-analysis serves as a springboard for randomized trials with the potential to modernize guidelines surrounding POAF management and prophylaxis.

\section{References}

1. Turagam MK, Mirza M, Werner PH, Sra J, Kress DC, Tajik AJ, et al. Circulating biomarkers predictive of postoperative atrial fibrillation. Cardiol Rev. 2016;24: 76-87.

2. Shen J, Lall S, Zheng V, Buckley P, Damiano RJ Jr, Schuessler RB. The persistent problem of new-onset postoperative atrial fibrillation: a single-institution experience over two decades. J Thorac Cardiovasc Surg. 2011;141:559-70.

3. Greenberg JW, Lancaster TS, Schuessler RB, Melby SJ. Postoperative atrial fibrillation following cardiac surgery: a persistent complication. Eur J Cardiothorac Surg. 2017;52:665-72.

4. Bessissow A, Khan J, Devereaux PJ, Alvarez-Garcia J, Alonso-Coello PA. Postoperative atrial fibrillation in non-cardiac and cardiac surgery: an overview. $J$ Thromb Haemost. 2015;13(Suppl 1):S304-12.
5. Kosmidou I, Chen S, Kappetein AP, Serruys PW, Gersh BJ, Puskas JD, et al. New-onset atrial fibrillation after PCI or CABG for left main disease: the EXCEL trial. J Am Coll Cardiol. 2018;71:739-48.

6. Auer J, Weber T, Berent R, Ng CK, Lamm G, Eber B. Risk factors of postoperative atrial fibrillation after cardiac surgery. J Card Surg. 2005;20:425-31.

7. Mathew JP, Fontes ML, Tudor IC, Ramsay J, Duke P, Mazer CD, et al. A multicenter risk index for atrial fibrillation after cardiac surgery. JAMA. 2004;291: 1720-9.

8. Caldonazo T, Kirov H, Rahouma M, Robinson NB, Demetres M, Gaudino M, et al. Atrial fibrillation after cardiac surgery: a systematic review and meta-analysis. J Thorac Cardiovasc Surg. 2023;165:94-103.e24.

9. Lin MH, Kamel H, Singer DE, Wu YL, Lee M, Ovbiagele B. Perioperative/postoperative atrial fibrillation and risk of subsequent stroke and/or mortality. Stroke 2019;50:1364-71.

10. Kaw R, Hernandez AV, Masood I, Gillinov AM, Saliba W, Blackstone EH. Shortand long-term mortality associated with new-onset atrial fibrillation after coronary artery bypass grafting: a systematic review and meta-analysis. $J$ Thorac Cardiovasc Surg. 2011;141:1305-12.

11. Megens MR, Churilov L, Thijs V. New-onset atrial fibrillation after coronary artery bypass graft and long-term risk of stroke: a meta-analysis. JAMA. 2017;6: $\mathrm{e} 007558$.

12. Eikelboom R, Sanjanwala R, Le ML, Yamashita MH, Arora RC. Postoperative atrial fibrillation after cardiac surgery: a systematic review and meta-analysis. Ann Thorac Surg. 2021;111:544-54.

13. January CT, Wann LS, Alpert JS, Calkins H, Cigarroa JE, Cleveland JC Jr, et al 2014 AHA/ACC/HRS guideline for the management of patients with atrial fibrillation: executive summary: a report of the American College of Cardiology/ American Heart Association task force on practice guidelines and the Heart Rhythm Society. Circulation. 2014;130:2071-104.

14. January CT, Wann LS, Calkins H, Chen LY, Cigarroa JE, Cleveland JC Jr, et al. 2019 AHA/ACC/HRS focused update of the 2014 AHA/ACC/HRS guideline for the management of patients with atrial fibrillation: a report of the American College of Cardiology/American Heart Association task force on clinical practice guidelines and the Heart Rhythm Society in collaboration with the Society of Thoracic Surgeons. Circulation. 2019;140:e125-51.

15. Gillinov AM, Bagiella E, Moskowitz AJ, Raiten JM, Groh MA, Bowdish ME, et al. Rate control versus rhythm control for atrial fibrillation after cardiac surgery. N Engl J Med. 2016;374:1911-21.

16. Society of Thoracic Surgeons (STS). Adult cardiac surgery database data collection. Available at: https://www.sts.org/registries-research-center/sts-nationaldatabase/adult-cardiac-surgery-database/data-collection. Accessed April 11, 2021

17. Matos JD, McIlvaine S, Grau-Sepulveda M, Jawitz OK, Brennan JM Khabbaz KR, et al. Anticoagulation and amiodarone for new atrial fibrillation after coronary artery bypass grafting: prescription patterns and 30-day outcomes in the United States and Canada. J Thorac Cardiovasc Surg. February 19, 2020 [Epub ahead of print].

18. National Institutes of Health, ClinicalTrials.gov. Anticoagulation for new-onset post-operative atrial fibrillation after CABG (PACES). Available at: https:// clinicaltrials.gov/ct2/show/NCT04045665. Accessed April 8, 2021.

19. Ip JE. Wearable devices for cardiac rhythm diagnosis and management. JAMA 2019;321:337-8. 